\title{
The Results of Autologous Skin Test in Patients with Chronic Urticaria in Hamadan, Iran
}

\author{
Mojgan Safari ${ }^{1}$, Hooshyar Sayemiri ${ }^{2}$
}

${ }^{1}$ M.D., Allergist and Clinical Immunologist, Associate Professor, Department of Immunology and Allergy, Faculty of Medicine, Hamadan University of Medical Sciences, Hamadan, Iran

${ }^{2}$ M.D., Medical and Health Network Manager of Marivan, Kurdistan University of Medical Sciences, Marivan, Iran

\section{Type of article: Short report}

\begin{abstract}
Introduction: The etiology of chronic urticaria is unknown in many cases. In this study, we demonstrated the presence of autoimmune antibodies in patients with chronic urticaria by using of the Autologous Serum Skin Test (ASST).

Methods: We performed a cross-sectional study to detect the presence of autologous antibodies in the serum of 38 patients (25 females and 13 males) with idiopathic chronic urticaria who were referred to the Hamedan Allergy Clinic in 2014. All of the necessary tests for demonstrating chronic urticaria were performed, including complete blood count $(\mathrm{CBC})$, thyroid and liver functionality tests, and the prick test but they did not confirm the cause of chronic urticaria. We conducted the Autologous Serum Skin Test on the patients and analyzed the results.

Results: In 15 patients (39\%), the ASST was positive. Of the 15 patients with positive autoimmune chronic urticaria, five patients (33\%) were males, and 10 patients $(67 \%)$ were females.

Conclusion: We concluded that many patients with chronic urticaria have autoimmune urticaria. It is the reason for the lack of the response to treatment with common medications for urticaria. New ways of treatment must be considered for them.
\end{abstract}

Keywords: Urticaria, Autologous serum skin test, Chronic

\section{Introduction}

Urticaria affects 15 to $30 \%$ of the general population, and approximately 0.5 to $1 \%$ of the cases are chronic. Chronic urticaria is a common and disturbing disease characterized by short-lived weals that occur daily or almost daily for at least six weeks with no identifiable cause in 70 to $80 \%$ of patients (1). The pathogenesis of chronic idiopathic urticaria is not entirely clear. In 1986, Grattan et al. reported that the intra-dermal injection of a serum factor led to the creation of weals in chronic urticarial patients (i.e., Autologous Serum Skin Test, ASST) (2). In 1993, Hide et al. suggested an autoimmune etiology for chronic idiopathic urticaria (3). At least one-third of patients with idiopathic chronic urticaria, ranging from 25 to $60 \%$, have circulating functional autoantibodies against the high-affinity $\operatorname{IgE}$ receptor Fc_RI, or less commonly, IgE (4). In clinical practice, a positive ASST is used as a method to determine the existence of auto-antibodies to FceRI and is assumed to express the presence of an autoimmune pathogenesis of urticaria $(5,6)$. The ASST is a reliable in vivo test; it is performed by injecting the patient's own serum into the skin, since it is able to reveal the chronic idiopathic urticaria auto reactivity (7). During the active phase of the disease, a weal and flare reaction may develop $(8,9)$. There is a correlation between a positive Autologous Serum Skin Test (ASST) and the presence of anti-FceRI and anti-IgE auto-antibodies (10). False positive results due to the formation of other vasoactive mediators while the serum is being processed and false negative results due to degradation of histamine-releasing factors may be induced (7). Although the basophil histamine release assay is the best standard for detecting auto-antibodies in chronic urticaria, it has its own difficultly because of the need for fresh basophiles

\section{Corresponding author:}

Associate Professor Dr. Mojgan Safari, Department of Immunology and Allergy, Faculty of Medicine, Hamadan University of Medical Sciences, Hamadan, Iran.

Tel: +98.8138268866, Fax: +98.8132640064, Email: mo_sfr@yahoo.com

Received: November 14, 2015, Accepted: May 03, 2016, Published: June 2016

iThenticate screening: March 31, 2016, English editing: May 17, 2016, Quality control: June 04, 2016

(C) 2016 The Authors. This is an open access article under the terms of the Creative Commons Attribution-NonCommercialNoDerivs License, which permits use and distribution in any medium, provided the original work is properly cited, the use is non-commercial and no modifications or adaptations are made. 
from the patient (1). Therefore, the ASST test is the only functional and cost-effective method for the diagnosis of autoimmune chronic urticaria. Our study was focused on evaluating the prevalence of positive ASST's in patients with chronic urticaria in the Hamedan geographical region.

\section{Material and methods}

This study consisted of patients who were referred to the Allergy Clinic with the chief complaint of hives for more than six weeks. Complete blood count (CBC) and erythrocyte sedimentation rate (ESR) tests, liver and thyroid functionality tests, and urine analysis (U/A), urine culture (U/C), stool examination $(\mathrm{S} / \mathrm{E})$ and skin allergens reviews were conducted, and all were normal. Patients were assumed not to have any exclusion criteria that could void the study, such as the existence of any other systemic disease in the previous reviews; any obvious causes for the hives; history of insect bites; recent usage of a drug; or vaccine and physical urticaria. We explained to the patients how the test was going to be performed as well as its probable implications and future trends in tests and treatment. We also imposed an obligation of not using drugs (antihistamines) for at least 48 hours before the test. Only if the patient agreed with the terms and conditions were the tests conducted. In the first stage, $5 \mathrm{~cm}^{3}$ of the patient's blood were sampled in a no heparin cast pipe and allowed to clot at room temperature. The patient's serum was centrifuged at $2000 \mathrm{rpm}$ for 15 minutes. Next, $0.05 \mathrm{~cm}^{3}$ of autologous serum was injected intradermally into the forearm, followed by the injection of the same amount of saline-as a control-in the opposite side. The results were read after 30 minutes. Indurations of more than $1.5 \mathrm{~mm}$ in diameter than that of the saline control were considered as positive results (11).

\section{Results}

In this study, 38 patients participated, 25 (66\%) females and $13(34 \%)$ males. The ASST was performed for all 38 patients. The ASST was positive in 15 patients (39\%) and negative in 23 patients (61\%). Out of 15 patients with autoimmune chronic urticaria, five patients $(33 \%)$ were males and $10(67 \%)$ were females. Out of 23 patients with non-autoimmune chronic urticaria, 15 patients $(65 \%)$ were females and eight $(35 \%)$ were males. The ages of the patients who participated in the study were between 7 and 60 . The ages of patients were between 1-10, 11-20,21-30, $31-40,41-50$, and 51-60 in 1, 3, 13, 8, 9, and 4 patients, respectively. Their mean age was 34 . Most of the patients were between the ages of 21 and 30 , and this group also had the highest number of positive test results. Due to the low number of the samples in the different age groups, the chi-squared test was not used. The percentage of positive results of the ASST in this study among the patients with chronic urticaria was $39 \%$.

\section{Discussion}

In our study, most of the chronic urticaria occurred in women, however, more research is required before we can generalize this finding. The major difficulties in the process of treating the patients with chronic urticaria were as follows. The treatments often were time consuming and energy wasting, which caused the quality of life of many of the patients to become downgraded drastically. This may persist for a long time. Moreover, the patients made demands of the doctors in various ways. They often sought a variety of drugs in addition to intolerable regimes, which were difficult and demanding. Considering the significant frequency of the occurrence of autoimmune urticaria among the patients with chronic urticaria, the ASST as a primary screening test is favorable, and it is easy to perform. In this study, 38 patients with chronic urticaria were screened. Twenty-five of them were females, and 13 were males. The difference in gender does not imply more frequent chronic urticaria in females. This may be due to the sensitivity among women or the higher number of female patients referred to the clinic and who participated in the test. Although we could not ignore the female dominance in the presentation of urticarial, especially the chronic form, it could be a clue for other researchers to prove this theory. In 10 out of 25 females (40\%) with chronic urticaria, the ASST test was positive. Also, in five out of 13 males (38\%), the ASST test was positive. Therefore, there was no correlation between the ASST results and the patient's gender. In the study of Emma Guttman on 32 patients with chronic urticaria, the ASST test was positive in $53 \%$ of the patients (8). Taskapan studied the results of the ASST test in patients with chronic urticaria in 2008 and mentioned that $52.5 \%$ had positive results. Taskapan found that patients with chronic urticaria have auto-antibodies with high affinity to FceRI $\alpha$ receptors, which leads to the release of histamine (12). Godse mentioned that the ASST is the only practical and available test for the diagnosis of autoimmune urticaria, with $70 \%$ sensitivity and $80 \%$ specificity. He studied 45 patients with chronic urticaria and reported the ASST as positive in $12(26 \%)$ cases, with the male to female ratio of 1 to 2 (13). In a study of 100 patients in 2008, Mametha (1) reported the ASST test as positive in $34 \%$ of the cases. Autologous serum skin tests were positive in $63.5 \%$ and $24 \%$ in patients with chronic urticaria in the studies of Colgecen et al. (14) and Lunge et al. (15), respectively. As mentioned before, our study consisted of 38 patients, and 
the ASST test was determined to be positive in 15 (39\%) cases. In other words, 39\% had autoimmune urticaria, and $61 \%$ had non-autoimmune urticaria. This conforms to the results of other researchers.

\section{Conclusions}

The adjustment or modification of the medication and food regimes has an important role in reducing the problems the patients are struggling with. It is essential to do more research to confirm whether the immunosuppressive drugs are effective enough to be the actual treatment for chronic autoimmune urticaria. We concluded that many patients with chronic urticaria have autoimmune urticaria. This is the reason for the lack of the response to treatment with common medications for urticaria. New ways of treatment must be considered for them.

\section{Acknowledgments:}

This article was extracted from a thesis prepared by Hooshyar Sayemiri to earn his medical doctorate degree. This study was funded by the Hamedan University of Medical Sciences under contract number IR.UMSHA.REC.1394.538. The authors thank Dr. Alireza Zamani for editing this article.

\section{Conflict of Interest:}

There is no conflict of interest to be declared.

\section{Authors' contributions:}

Both authors contributed to this project and article equally. Both authors read and approved the final manuscript.

\section{References:}

1) George M, Balachandran C, Probhn S. Chronic idiopathic urticaria: comparison of clinical features with positive autologous serum skin test. Indian J Dermatol Venereol Leprol. 2008; 74: 105-8. doi: 10.4103/0378-6323.39690. PMID: 18388365.

2) Grattan CE, Wallington TB, Warin RP, Kennedy CT, Bradfield JW. A serological mediator in chronic idiopathic urticaria-a clinical, immunological and histological evaluation. Br J Dermatol. 1986; 114: 58390 . doi: 10.1111/j.1365-2133.1986.tb04065.x. PMID: 3718848.

3) Hide M, Francis DM, Grattan CE, Hakimi J, Kochan JP, Greaves MW. Autoantobodies against the highaffinity IgE receptor as a cause of histamine release in chronic urticaria. N Engl J Med. 1993; 328: 1599604. doi: 10.1056/NEJM199306033282204. PMID: 7683772.

4) Fiebiger E, Maurer D, Holub H, Reininger B, Hartmann G, Woisetschläger M, et al. Serum IgG autoantibodies directed against the alpha chain of Fc epsilon RI. A selective marker and pathogenetic factor for a distinct subset of chronic urticarial patients? J Clin Invest. 1995; 96: 2606-12. doi: 10.1172/JCI118325. PMID: 8675625, PMCID: PMC185965.

5) Fusari A, Colangelo C, Bonifazi F, Antonicelli L. The autologous serum skin test in the follow-up of patients with chronic urticaria. Allergy. 2005; 60(2): 256-8. doi: 10.1111/j.1398-9995.2005.00673.x. PMID: 15647050 .

6) Greaves MW. Pathophysiology of chronic urticaria. Int Arch Allergy Immunol. 2002; 127: 3-9. doi: 10.1159/000048163, PMID: 11893848.

7) Sabroe RA, Grattan CE, Francis DM, Barr RM, Kobza Black A, Greaves MW. The autologous serum skin test: a screening test for autoantibodies in chronic idiopathic urticaria. Br J Dermatol. 1999; 140: 446- 52. doi: 10.1046/j.1365-2133.1999.02707.x. PMID: 10233264.

8) Guttman-Yassky E, Bergman R, Maor C, Mamorsky M, Pollack S, Shahar E. The autologous serum skin test in a cohort of chronic idiopathic urticaria patients compared to respiratory allergy patients and healthy individuals. J Eur Acad Dermatol Venereol. 2007; 21(1): 35-9. doi: 10.1111/j.1468-3083.2006.01852.x. PMID: 17207165 .

9) Toubi E, Kessel A, Avshovich N, Bamberger E, Sabo E, Nusem D, et al. Clinical and laboratory parameters in predicting chronic urticaria duration: a prospective study of 139 patients. Allergy. 2004; 59: 869-73. doi: 10.1111/j.1398-9995.2004.00473.x. PMID: 15230821.

10) Asero R, Lorini M, Chong SU, Zuberbier T, Tedeschi A. Assessment of histamine-releasing activity of sera from patients with chronic urticaria showing positive autologous skin test on human basophils and mast cells. Clin Exp Allergy. 2004; 34: 1111-4. doi: 10.1111/j.1365-2222.2004.01997.x. PMID: 15248858.

11) Asero $R$, Tedeschi A. Is puncture skin test adequate to detect autoreactivity in patients with chronic urticaria? Clin Exp Dermatol. 2008; 33: 776-94. doi: 10.1111/j.1365-2230.2008.02880.x. PMID: 18627389 . 
12) Taskapan O, Kutlu A, KarabudakO.Evaluation of autologous serum skin test results in patients with chronic idiopathic urticaria, allergic / non-allergic asthma or rhinitis and healthy people. Clin Exp Dermatol. 2008; 33(6): 754-8. doi: 10.1111/j.1365-2230.2008.02819.x. PMID: 18954415.

13) Godse KV. Autologous Serum Skin Test in Chronic idiopathic Urticaria. Indian J Dermatol Venereol Leprol. 2004; 70(5): 283-4. PMID: 17642638.

14) Colgecen E, Ozyurt K, Gul AI, Utas S. Evaluation of etiological factors in patients with chronic urticaria. Acta Dermatovenerol Croat. 2015; 23(1): 36-42. PMID: 25969911.

15) Lunge SB, Borkar M, Pande S. Correlation of serum antithyroid microsomal antibody and autologous serum skin test in patients with chronic idiopathic urticaria. Indian Dermatol Online J. 2015; 6(4): 248-52. doi: 10.4103/2229-5178.160255, PMID: 2622532, PMCID: PMC4513403. 